\title{
Perfil do PPPGCOM em Comunicação Midiática da UNESP: Análise de dissertações - Biênio 2013/2014
}

\author{
Relatório de Pesquisa
}

Daira Martins Botelho

Doutoranda do Programa de Pós-Graduação em Comunicação da UNESP.

Henrique Perazzi de Aquino

Mestrando do Programa de Pós-Graduação em Comunicação Midiática da UNESP.

Maria Cristina Gobbi

Profa. Adj. no Departamento de Comunicação Social e do Programa de Pós-Graduação da UNESP.

Laís Modelli

Mestranda do Programa de Pós-Graduação em Comunicação Midiática da UNESP.

Camila Fenandes de Oliveira

Mestranda do Programa de Pós-Graduação em Comunicação Midiática da UNESP.

Aline Ferreira Pádua

Mestranda do Programa de Pós-Graduação em Comunicação Midiática da UNESP.

Juliano Ferreira de Souza

Mestre em Comunicação Midiática pela UNESP.

\section{Resumo}

O artigo traz a proposta do mapeamento das dissertações produzidas pelos discentes da Linha 1 - Processos midiáticos e práticas socioculturais, do Programa de Pós-Graduação em Comunicação Midiática da Faculdade de Arquitetura, Artes e Comunicação (Faac) of Universidade Estadual Paulista "Julio de Mesquita Filho" (Unesp), campus de Bauru, com o objetivo de delinear questões importantes que remetessem à identidade do Programa. Foram analisados, entre outros aspectos, o uso de autores, o tipo de material usado pelos discentes, além das teorias que serviram para embasar suas pesquisas. Trata-se do resultado da proposta de trabalho indicada pela Profa. Dra. Maria Cristina Gobbi, na disciplina ministrada no segundo semestre de 2014, Pensamento Comunicacional Latino-americano.

Palavras-chave: Comunicação; Dissertações; PPGCom Unesp.

\section{Abstract}

This paper proposes a mapping of master dissertations produced by students of Research Line 1 - Media processes and socio-cultural practices, of the Programa de Pós-Graduação em Comunicação Midiática of Faculdade de Arquitetura, Artes e Comunicação (Faac) of Universidade Estadual Paulista "Julio de Mesquita Filho" (Unesp), Bauru campus, in order to outline important issues connected with program identity. Among the analyzed aspects are the referenced authors, the type of material used by students, in addition to theories that served to support their research. This is the result of the work proposal indicated by Professor Maria Cristina Gobbi in the subject taught in the second 
Perfil do PPPGCOM em Comunicação Midiática da UNESP:

Análise de dissertações - Biênio 2013/2014

term of 2014, Latin American Communicational Thought.

Keywords: Communication; Dissertations; PPGCom Unesp.

\section{Resumen}

El artículo presenta la propuesta de la cartografia de disertaciones producidas por los estudiantes de la Línea 1 - Procesos de los medios de comunicación y las prácticas socioculturales, en el Programa de Pós-graduação en Comunicação Midiática de la Faculdade de Arquitetura, Artes e Comunicação (Faac) of Universidade Estadual Paulista "Julio de Mesquita Filho" (Unesp), Bauru campus, con el fin de esbozar cuestiones importantes que remetessem a la identidad del Programa. Se analizaron, entre otras cosas, el uso de los autores, el tipo de material utilizado por los estudiantes, además de las teorías que sirvieron para apoyar sus investigaciones. Este es el resultado de la propuesta de trabajo indicada por el Profa ${ }^{\text {a }}$ Dra ${ }^{a}$. María Cristina Gobbi en el tema enseñado en la segunda mitad de 2014, Pensamiento Comunicacional en Latino America.

Palabras clave: Comunicación; Disertaciones; PPGCom Unesp.

\section{Introdução}

Este trabalho foi realizado para a disciplina Pensamento Comunicacional Latino-americano (PCLA), ministrada pela Prof ${ }^{\mathrm{a}}$. Dra. Maria Cristina Gobbi. Realizou-se a compilação de dados e referenciais teóricos de projetos acadêmico-científicos. Foram selecionadas 16 dissertações, apresentadas junto ao Programa de Pós Graduação em Comunicação Midiática da Faculdade de Arquitetura, Artes e Comunicação no biênio 2013/2014.

Todas as pesquisas analisadas são vinculadas à Linha 1 - Processos Midiáticos e Práticas Socioculturais. Deste conjunto, catorze trabalhos estavam disponíveis no site do programa e os demais foram obtidos por contato direto com os pesquisadores. As pesquisas tratam de questões que travam diálogos entre cultura e comunicação e colocam em cena diversas possibilidades para reflexão.

O grupo que realizou a presente análise foi composto por seis alunos, e o material foi dividido entre os membros para análise quantitativa e qualitativa. Estabeleceu-se uma metodologia a ser seguida por todos. A ferramenta comum foi uma ficha de dissertação na qual cada um preencheria alguns itens. $\mathrm{O}$ instrumento considerou bases teóricas, autores de referências para citações (incluindo os considerados secundários) e datas das publicações de referência. Foram também ressaltadas referências aos orientadores e pesquisadores do programa. Ao final, houve um cruzamento das análises em grupo e os dados foram compilados em formato de gráficos e tabelas.

Tem-se, como desdobramento, a possibilidade de que o resultado final possa ser uma espécie de guia para os futuros pesquisadores, que se beneficiarão com informações acerca da trajetória e dos rumos científicos da referida linha de pesquisa.

\section{Amostragem e metodologia}

O corpus da pesquisa é composto por 16 dissertações defendidas no biênio 2013/2014 dentro da Linha 1 - Processos midiáticos e práticas socioculturais - do Programa de Pós-graduação em Comunicação Midiática da Unesp (PPGCom). Essa linha de pesquisa tem como foco de investigação as dimensões socioculturais dos processos de produção, veiculação e recepção da comunicação midiática. 
As dissertações analisadas não pertencem ao mesmo eixo temático, com as discussões levantadas pelos alunos e professores abrangendo um amplo leque de temas em torno da comunicação e das práticas socioculturais. Os trabalhos que debatem cultura e/ ou comunicação e cultura ganham certo destaque dentro da linha. Entre as teorias utilizadas nas pesquisas, as mais utilizadas são Estudos Culturais e Estudos Latino-americanos. Em relação aos métodos de análise ganham destaque: levantamento bibliográfico e documental; análise de enquadramento; análise de conteúdo.

Para a análise das referidas dissertações realizou-se, inicialmente, uma análise exploratória dos materiais, observando bibliografias e tipo de material utilizado pelos alunos no desenvolvimento dos trabalhos. Na sequência, foi feita a análise quantitativa dos materiais. Nessa fase procurou-se catalogar informações que permitissem avaliar o tipo de pesquisa desenvolvida pelo grupo e, assim, traçar o perfil de pesquisa acadêmica da linha 1 do PPGCom da Unesp. Para tanto, foi desenvolvida uma tabulação padrão, com título da dissertação, autor, orientador, palavras-chave, mídia estudada, temática, teoria de base, metodologia, referências e tipo de material consultado. Esses dois últimos itens foram desdobrados nos seguintes tópicos:

1. Em referências: autor, origem, aparição em referências, título da obra, ano de publicação, citação direta, citação indireta, citado por outro autor, organizador de livro;

2. Em tipo de material consultado: livro, capítulo de livro, dissertação, tese, artigo cientifico - anais de congresso, artigo científico - revista científica, jornal, sites, entrevistas, revistas, acervo digital (jornal, revista), manuscritos, dicionários, etc.

A partir dos dados levantados foi possível tabular e organizar índices e frequências e, por meio da análise qualitativa, delinear o perfil de pesquisa acadêmica desenvolvida dentro da linha 1 do programa e, assim, verificar como se dá a difusão dos paradigmas da Escola Latino-Americana de Comunicação. A seguir, as dissertações analisadas e, posteriormente, a discussão dos dados e os resultados alcançados.

Tabela 01 - Dissertações pesquisadas, autores e orientadores - Autoria própria

\begin{tabular}{|c|c|c|c|}
\hline Ano & Dissertação & Aluno & Orientador \\
\hline 2013 & $\begin{array}{l}\text { Representação do Corpo Masculino: relações de } \\
\text { imagem, identidade e cultura sobre o corpo mas- } \\
\text { culino no jornal Lampião da Esquina e na revista } \\
\text { Junior }\end{array}$ & $\begin{array}{l}\text { Muriel Emídio Pessoa do } \\
\text { Amaral }\end{array}$ & Cláudio Bertolli Filho \\
\hline 2013 & $\begin{array}{l}\text { Identidade, comunicação e cidadania no Facebook: } \\
\text { uma análise do diário de classe de Isadora Faber }\end{array}$ & Silvia Regina Ferreira & Cláudio Bertolli Filho \\
\hline 2014 & $\begin{array}{l}\text { Jovens Conectados: A comunicação da Igreja Católi- } \\
\text { ca no contexto da Jornada Mundial da Juventude }\end{array}$ & $\begin{array}{l}\text { Aline Maria Mendes Mola } \\
\text { Sávio }\end{array}$ & Maria Cristina Gobbi \\
\hline 2013 & $\begin{array}{l}\text { Demochargia: Dilma Rousseff e seu primeiro ano de } \\
\text { mandato pelas charges jornalísticas }\end{array}$ & Cristiane dos Santos Parnaíba & Maria Cristina Gobbi \\
\hline 2014 & $\begin{array}{l}\text { Telejornalismo na TVD: interatividade e mudanças } \\
\text { na rotina da redação. }\end{array}$ & Selma Miranda dos Prazeres & Maria Cristina Gobbi \\
\hline 2013 & $\begin{array}{l}\text { Consumir e descartar: Análise da cobertura da } \\
\text { Folha de S. Paulo e Jornal da Cidade no caso da } \\
\text { proibição da distribuição das sacolas plásticas nos } \\
\text { supermercados do Estado de São Paulo }\end{array}$ & Ana Carolina Milo Britto & Mauro de Souza Ventura \\
\hline
\end{tabular}




\begin{tabular}{|c|c|c|c|}
\hline Ano & Dissertação & Aluno & Orientador \\
\hline 2014 & $\begin{array}{l}\text { "Sou Atleta, Sou Mulher": A Representação Femi- } \\
\text { nina Sob Análise Das Modalidades Mais Noticiadas } \\
\text { Nas Olimpíadas De Londres } 2012\end{array}$ & Carolina Bortoleto Firmino & Mauro de Souza Ventura \\
\hline 2014 & $\begin{array}{l}\text { Jornal ‘Coração', o Porta-Voz da Torcida Corintia- } \\
\text { na: Uma aventura na Imprensa Esportiva Paulista } \\
(1976 / 1977)\end{array}$ & $\begin{array}{l}\text { Fábio Camargo Fleury de } \\
\text { Oliveira }\end{array}$ & Mauro de Souza Ventura \\
\hline 2013 & $\begin{array}{l}\text { Jornalismo e Cultura de Consumo: Uma análise da } \\
\text { Revista Rolling Stone - Brasil }\end{array}$ & Thaís Helena Paixão & Mauro de Souza Ventura \\
\hline 2013 & A representação do caipira na UNESP FM & $\begin{array}{l}\text { Wellington César Martins } \\
\text { Leite }\end{array}$ & Mauro de Souza Ventura \\
\hline 2013 & $\begin{array}{l}\text { Interação Comunitária: O Cidadão em Sintonia } \\
\text { Radiofônica }\end{array}$ & Aline Meneguini de Oliveira & Maximiliano Martin Vicente \\
\hline 2014 & O semanário Bundas e o jornalismo econômico & Caroline Gonçalves Taveira & Maximiliano Martin Vicente \\
\hline 2013 & $\begin{array}{l}\text { Os processos de comunicação interna das organi- } \\
\text { zações no contexto das tecnologias da comunicação } \\
\text { digital: Reflexões a partir das práticas de interativi- } \\
\text { dade da geração y }\end{array}$ & $\begin{array}{l}\text { Fernanda Terezinha de } \\
\text { Almeida }\end{array}$ & Maximiliano Martin Vicente \\
\hline 2014 & $\begin{array}{l}\text { A participação das mulheres nos movimentos } \\
\text { agroecológico e feminista e a contribuição do jornal } \\
\text { Brasil de Fato }\end{array}$ & $\begin{array}{l}\text { Suelyn Cristina Carneiro da } \\
\text { Luz }\end{array}$ & Maximiliano Martin Vicente \\
\hline 2014 & $\begin{array}{l}\text { Os eventos como estratégia de Comunicação em } \\
\text { Movimentos Sociais: Um Estudo de Caso sobre a } \\
\text { Parada da Diversidade de Bauru }\end{array}$ & $\begin{array}{l}\text { Elaine Cristina Gomes de } \\
\text { Moraes }\end{array}$ & Murilo Cesar Soares \\
\hline 2014 & $\begin{array}{l}\text { Das ideias de Roland Barthes à teoria do enquadra- } \\
\text { mento: análise de uma cobertura política }\end{array}$ & $\begin{array}{l}\text { João Guilherme da Costa } \\
\text { Franco Silva D'Arcadia }\end{array}$ & Murilo Cesar Soares \\
\hline
\end{tabular}

\section{Discussão dos dados e resultados}

\section{Materiais usados nas pesquisa}

A pesquisa nas dissertações de mestrado também abordou os materiais utilizados pelos discentes, com o objetivo de conhecer o meio pelo qual se constroem o referencial teórico, as metodologias e toda a análise em si.

Entre as publicações desenvolvidas na linha 1 do programa, pode-se notar uma predominância do uso de livros como material de base para as consultas e construção de pensamento. Esse item foi encontrado com maioria expressiva em praticamente todas as dissertações consultadas. Isso leva a crer que, mesmo com a disseminação de informação por meio de artigos e demais publicações científicas, o livro ainda é o grande referencial buscado pelos alunos pertencentes a essa linha de pesquisa.

Em segundo lugar, no que tange aos números, os capítulos de livros são os que aparecem em maior número, reiterando o que foi dito acima sobre a predominância dos livros - mesmo que em capítulos - na hora de compor o quadro de referências das dissertações.

Os artigos científicos entram nessa tríade para fechar os mais utilizados para a pesquisa enquanto um objeto é analisado. Dessa maneira, fica evidente que, apesar da grande quantidade de periódicos online assinados pela instituição, congressos, da produção e divulgação de anais e publicações dos eventos, os pesquisadores da linha 1 não possuem o hábito de procurar em periódicos as bases para suas análises ou recorrer a eles como parte de seu referencial.

O mesmo ocorre com a consulta a produções acadêmicas. A partir da pesquisa, foi possível perceber que não é comum a prática do uso desse tipo de estudo como arcabouço teórico. Dentre 
todos os materiais vistos no quadro de referência dos autores, encontraram-se duas monografias, 14 dissertações de mestrado e 13 teses de doutorado. De maneira comparativa, as publicações acadêmicas estão em minoria em relação aos artigos publicados em anais de congressos, contabilizados em 37, e em artigos de periódicos, que somam 93.

O que está especificado como "outros" no gráfico a seguir deve ser compreendido como uma enorme gama de materiais que colaboraram para a produção das dissertações, mas que aparecem em menor número, como jornal online, entrevista ao autor, revista, acervo digital de jornal impresso, manuscrito, posfácio, documentário, programa de TV e rádio, relatório de pesquisa, documentos públicos, pesquisas de institutos, documentos de eventos científicos (dossiê, carta política), sites em geral (com links em notas de rodapé, mas não nas referências finais), dicionários, documentos religiosos oficiais e palestras. Todos esses itens compõem os $14 \%$ existentes no quesito outros, que pode ser conferido no gráfico que segue e que traz, em porcentagem, todos os materiais encontrados nas dissertações pesquisadas.

Em relação ao tipo de publicações, foi encontrado o número de 1120 itens que colaboraram para a conclusão das pesquisas propostas ao Programa de Pós-graduação em Comunicação.

\title{
Gráfico 01 - Referências consultadas - Autoria própria
}

\section{Tipos de publicações}

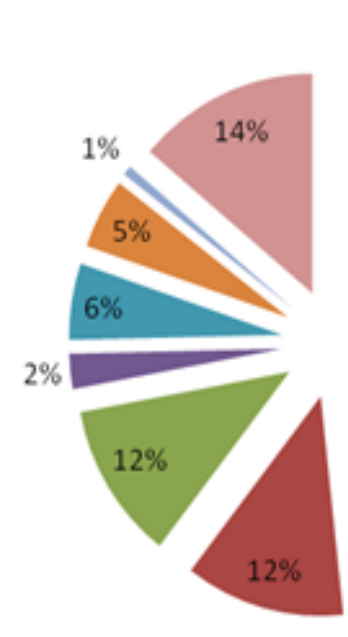

\author{
Livrose e-books \\ apítulos de Livro \\ artigos cientificos \\ - Teses, dissertaçōes e \\ monografias \\ n Publicaçōes periódicas não \\ cientificas \\ ansites \\ Entrevistas \\ Eutros
}

\section{Atualização de pensamento}

Os dados quantitativos também foram recolhidos para verificar qual a idade dos estudos realizados pelos alunos da linha 1 . E, nesse quesito, pode-se comprovar que se trata de uma linha com pensamentos relativamente novos, pois dentre todos os títulos encontrados nas referências, houve uma predominância da década de 1990 para os materiais pesquisados.

Para comparação, nas décadas que vão de 1950 até 1980, o número de itens somados chega a 98. Já no espaço de dez anos da década de 1990, as obras utilizadas somam 145. Mas a partir dos anos 2000, o referencial teórico se torna consideravelmente expressivo, com uma marca de 750 itens, distribuídos entre os anos de 2000 e 2014, como pode ser melhor analisado de acordo com os números dispostos na tabela. 
Tabela 02 - Referencial teórico por ano - Autoria própria

\begin{tabular}{|c|c|}
\hline Período & Títulos \\
\hline Década de 50 & 1 \\
\hline Década de 60 & 11 \\
\hline Década de 70 & 21 \\
\hline Década de 80 & 65 \\
\hline Década de 90 & 145 \\
\hline 2000 & 24 \\
\hline 2001 & 45 \\
\hline 2002 & 50 \\
\hline 2003 & 50 \\
\hline 2004 & 43 \\
\hline 2005 & 48 \\
\hline 2006 & 55 \\
\hline 2007 & 52 \\
\hline 2008 & 47 \\
\hline 2009 & 92 \\
\hline 2010 & 63 \\
\hline 2011 & 86 \\
\hline 2012 & 61 \\
\hline 2013 & 31 \\
\hline 2014 & 3 \\
\hline & \\
\hline & \\
\hline
\end{tabular}

\section{Nacionalidades dos autores}

A nacionalidade dos autores utilizados nas referências dos trabalhos também foi pesquisado, para buscar compreender se, de alguma maneira, isso teria influenciado nas dissertações, sobretudo em âmbito da América Latina, já que o que se buscou durante a disciplina foi trabalhar as Matrizes comunicacionais existentes nessa região e seus impactos na comunicação em geral, por isso, dimensionar o uso dos autores latino americanos foi uma intervenção necessária para observar como os discentes estariam trabalhando com os autores mais próximos do Brasil e, consequentemente, com maior afinidade em relação ao enfrentamento de problemas e realidades socioeconômicas e históricas.

Dessa maneira, foram buscadas as nacionalidades de todos os autores citados nas referências utilizadas pelos mestrandos do PPGCom e, assim, foi encontrado o resultado mostrado no gráfico.

Gráfico 02 - Nacionalidade dos autores mais citados - Autoria própria 


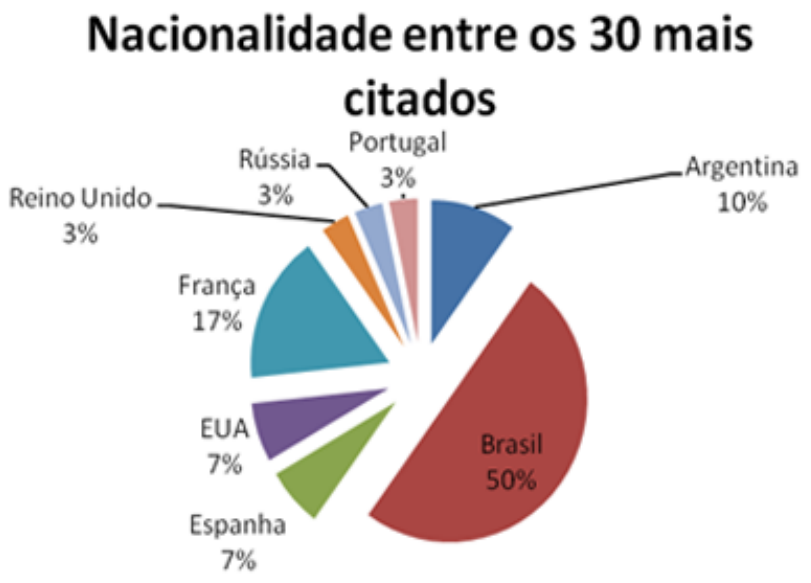

Após a coleta de dados e o cruzamento dos números para a confecção dos gráficos, pode-se perceber que na produção da linha é expressivo o número de autores brasileiros, que somam 50\% do total dos 30 autores mais citados nas referências dos trabalhos. A América Latina chega, também com expressividade, contabilizando $10 \%$ da nacionalidade desses 30 autores, representados aqui, por autores argentinos.

Grande parte do restante das fatias dispostas no gráfico diz respeito a autores europeus, que se dividem entre Espanha, Reino Unido, Rússia, Portugal e França, sendo que, esta última possui maior número de autores, $17 \%$. Isso se deve à força dos estudos de autores como Pierre Bourdieu, Roland Barthes, Manuel Castells e Laurence Bardin, por exemplo, que fazem parte de teorias que serão abordadas em outro ponto deste trabalho. Ainda com uma fatia de $7 \%$, aparecem os Estados Unidos, com números significativos para os trabalhos de Henry Jenkins.

Quando se trata dos números em relação à citação - tanto direta, quanto indireta -, o encontrado foi um pouco diferente do que pôde ser visto no gráfico anterior, no entanto, essa alteração não difere a questão proporcional dos números no que tange às nacionalidades mais utilizadas.

Uma das diferenças é uma ligeira queda no uso dos autores dos Estados Unidos e o aumento de sete pontos percentuais no uso de autores de nacionalidade francesa. Há também uma troca de números entre Brasil, que perde $8 \%$ e a Argentina, que cresce $4 \%$.

Gráfico 03 - Presença em citações e nacionalidade dos mais citados - Autoria própria 


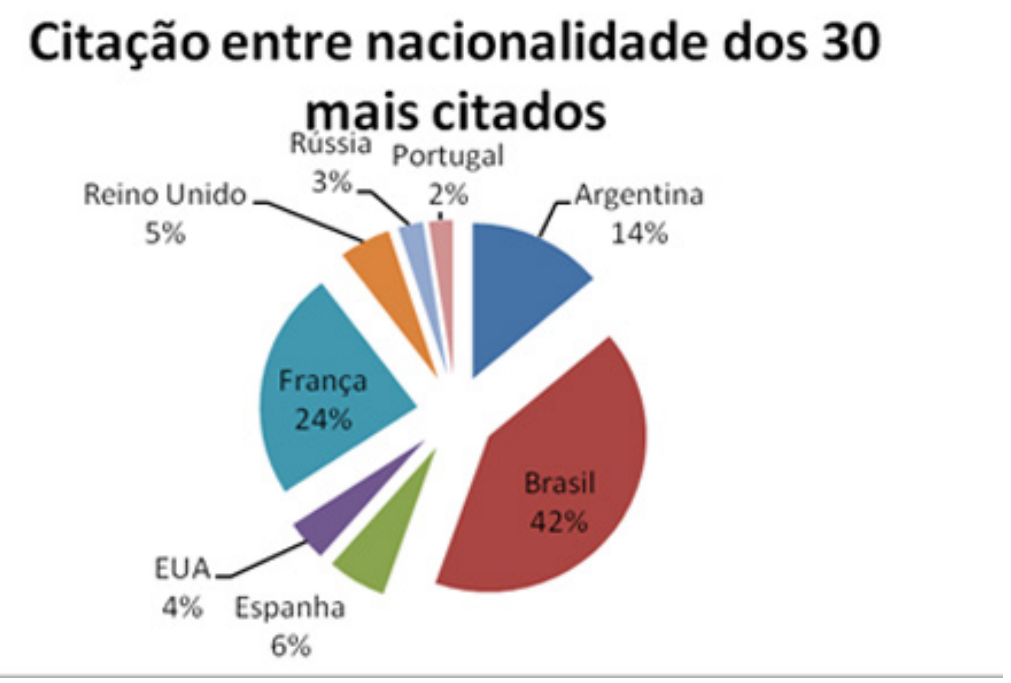

Entre os 30 autores mais citados, foi encontrado o número de 887 citações. Sendo 123 de argentinos, 369 de brasileiros, 54 de espanhóis, 35 de norte-americanos, 211 de franceses, 47 de autores do Reino Unido, 23 de russos e 22 de portugueses.

\section{Autores}

Diante da proposta de pesquisa, um dos temas a serem verificados foi a ocorrência dos autores mais utilizados pelos discentes da linha em suas dissertações de mestrado. Os dados coletados mostraram as influências que as pesquisas trazem por meio da escolha do referencial teórico - representado por maior uso de determinado autor -, essa informação é de grande importância para se pensar na unidade do pensamento do que poderia ser chamado de "Escola de Comunicação de Unesp".

Os números levaram a uma relação dos 30 autores com maior ocorrência de citações dentro das dissertações do PPGCom. O mais citado entre todos os autores foi o francês Roland Barthes, com uma quantidade expressiva de 119 citações. Em seguida aparece o argentino Néstor Garcia Canclini, que aparece em praticamente todas as pesquisas do mestrado, com um total de 65 citações. Figurando entre 40 citações no total de dissertações analisadas, aparecem José Marques de Melo (48), Mike Featherstone (47) e Beatriz Sarlo (40). Mais brasileiros aparecem entre os dez primeiros autores, são eles Margarida Maria Krohling Kunsch (36), Joaquim da Fonseca (31) e Marlene Marchiori (30).

Em seguida aparecem Laurence Bardin, com 29 citações, Lucia Santaella e Bernardo Kucinski, com 28, Manuel Castells e Jesús-Matín Barbero, ambos com 27 citações. Ainda representando os brasileiros aparecem Raquel Recuero e Nelson Traquina com 24 citações. Dulcilia Helena Schroeder Buitoni aparece 23 vezes, assim como Mikhail Bakhtin. Pierre Lévy chega a 22 citações, mesmo número de Paulo Freire. Já Henry Jenkins tem 21 citações e Patrick Charaudeau, 19.

No restante dos autores mais citados, encontra-se Mário Kaplún e Joana T. Puntel, ambos com 18 referências, Lúcia Avelar, Gaudêncio Torquato, Emma Siliprandi e David Kirkpatrick com 17 citações no total dos trabalhos. Para fechar a lista dos mais citados, aparecem Amadeu Amaral 
e Pierre Bourdieu, os dois com 16 citações cada.

De acordo com a coleta de dados, foi possível conhecer os autores brasileiros anteriormente representados nos gráficos. Com isso, reitera-se a importância e aparição de autores brasileiros, com destaque para José Marques de Melo e para Néstor Garcia Canclini que, juntos, apareceram significativamente como representantes do pensamento cultural e comunicacional da América Latina.

Durante a análise dos dados quantitativos, um dos assuntos chamou a atenção foi a predominância do uso de um autor em um número pequeno de dissertações, o que fez com que tal autor possuísse um grande percentual em relação a outros. No entanto, isso quer dizer que tais autores foram usados em pesquisas isoladas, e, não necessariamente, representem o total pensamento da linha ou do programa.

O autor mais citado entre os 30 foi Roland Barthes, com 119 citações, no entanto, foram três dissertações que utilizaram seus estudos, com destaque para a pesquisa de João Guilherme da Costa Franco Silva D’Arcadia, que possui mais da metade do número de citações apenas nessa publicação.

Outro exemplo pode ser visto a partir da aparição de Mike Featherstone, autor que tem mais da metade das citações usadas na dissertação de Thaís Helena Paixão além de aparecer em duas das pesquisas do PPGCom.

Apesar desse tipo de situação, existem autores que não possuem predominância em nenhum trabalho específico, ou seja, permeiam todas as dissertações produzidas pelos discentes da linha 1, entre eles estão: Néstor Garcia Canclini, José Marques de Melo, Laurence Bardin, Manuel Castells e Pierre Bourdieu.

Os outros autores que aparecem mais e suas respectivas posições entre as dissertações podem ser conferidas na tabela:

Tabela 03 - Predominância de autores nas dissertações - Autoria própria

\begin{tabular}{|c|c|c|c|c|c|}
\hline Autor & $\begin{array}{l}\text { Total de } \\
\text { citações }\end{array}$ & $\begin{array}{c}\text { Dissertações } \\
\text { que citam }\end{array}$ & $\begin{array}{l}\text { Dissertação com } \\
\text { mais da metade } \\
\text { das citações }\end{array}$ & $\begin{array}{l}\text { Quantas } \\
\text { citações }\end{array}$ & $\begin{array}{l}\text { Quantas } \\
\text { referências }\end{array}$ \\
\hline Roland Barthes & 119 & 3 & $\begin{array}{l}\text { João Guilherme da } \\
\text { Costa Franco Silva } \\
\text { D'Arcadia }\end{array}$ & 113 & 8 \\
\hline Nestor Garcia Canclini & 65 & $\begin{array}{l}\text { Não há } \\
\text { predominância }\end{array}$ & - & - & - \\
\hline José Marques de Melo & 48 & $\begin{array}{l}\text { Não há } \\
\text { predominância }\end{array}$ & - & - & - \\
\hline Mike Featherstone & 47 & 2 & $\begin{array}{l}\text { Thais Helena } \\
\text { Paixão }\end{array}$ & 46 & 1 \\
\hline Beatriz Sarlo & 40 & 1 & $\begin{array}{l}\text { Thais Helena } \\
\text { Paixão }\end{array}$ & 40 & 1 \\
\hline Margarida Maria Krohling Kunsch & 36 & 2 & $\begin{array}{l}\text { Fernanda Terezi- } \\
\text { nha de Almeida }\end{array}$ & 34 & 3 \\
\hline
\end{tabular}


Perfil do PPPGCOM em Comunicação Midiática da UNESP:

\begin{tabular}{|c|c|c|c|c|c|}
\hline Autor & $\begin{array}{l}\text { Total de } \\
\text { citações }\end{array}$ & $\begin{array}{l}\text { Dissertações } \\
\text { que citam }\end{array}$ & $\begin{array}{c}\text { Dissertação com } \\
\text { mais da metade } \\
\text { das citações }\end{array}$ & $\begin{array}{l}\text { Quantas } \\
\text { citações }\end{array}$ & $\begin{array}{l}\text { Quantas } \\
\text { referências }\end{array}$ \\
\hline Joaquim da Fonseca & 31 & 2 & $\begin{array}{l}\text { Cristiano dos } \\
\text { Santos Parnaíba }\end{array}$ & 28 & 1 \\
\hline Marlene Marchiori & 30 & 1 & $\begin{array}{l}\text { Fernanda Terezi- } \\
\text { nha de Almeida }\end{array}$ & 30 & 1 \\
\hline Laurence Bardin & 29 & $\begin{array}{l}\text { Não há } \\
\text { predominância }\end{array}$ & - & - & - \\
\hline Manuel Castells & 27 & $\begin{array}{l}\text { Não há } \\
\text { predominância }\end{array}$ & - & - & - \\
\hline Jesús Martín-Barbero & 27 & 5 & $\begin{array}{l}\text { Wellington César } \\
\text { Martins Leite }\end{array}$ & 14 & 2 \\
\hline Lucia Santaella & 28 & 1 & $\begin{array}{l}\text { Muriel Emídio } \\
\text { Pessoa do Amaral }\end{array}$ & 28 & 5 \\
\hline Raquel Recuero & 24 & 1 & $\begin{array}{l}\text { Silvia Regina } \\
\text { Ferreira }\end{array}$ & 24 & 5 \\
\hline Nelson Traquina & 24 & 4 & $\begin{array}{l}\text { Ana Carolina Milo } \\
\text { Britto }\end{array}$ & 13 & 2 \\
\hline Dulcília Helena Schroeder Buitoni & 23 & 1 & $\begin{array}{l}\text { Cristiano dos } \\
\text { Santos Parnaíba }\end{array}$ & 23 & 1 \\
\hline Mikhail Bakhtin & 23 & 2 & $\begin{array}{l}\text { Wellington César } \\
\text { Martins Leite }\end{array}$ & 22 & 1 \\
\hline Bernardo Kucinski & 28 & 3 & $\begin{array}{l}\text { Caroline Gonçal- } \\
\text { ves Taveira }\end{array}$ & 22 & 3 \\
\hline Pierre Lévy & 22 & 2 & $\begin{array}{l}\text { Fernanda Terezi- } \\
\text { nha de Almeida }\end{array}$ & 13 & 4 \\
\hline Paulo Freire & 22 & 3 & $\begin{array}{l}\text { Suelyn Cristina } \\
\text { Carneiro da Luz }\end{array}$ & 20 & 3 \\
\hline Henry Jenkins & 21 & 4 & $\begin{array}{l}\text { Fernanda Terezi- } \\
\text { nha de Almeida }\end{array}$ & 11 & 1 \\
\hline Patrick Charaudeau & 19 & 2 & $\begin{array}{l}\text { Ana Carolina Milo } \\
\text { Britto }\end{array}$ & 14 & 1 \\
\hline Mário Kaplún & 18 & 1 & $\begin{array}{l}\text { Wellington César } \\
\text { Martins Leite }\end{array}$ & 18 & 1 \\
\hline $\begin{array}{l}\text { Conferência Nacional dos Bispos do } \\
\text { Brasil (CNBB) }\end{array}$ & 18 & 1 & $\begin{array}{l}\text { Aline Maria Men- } \\
\text { des Mola Sávio }\end{array}$ & 18 & 3 \\
\hline Joana T. Puntel & 18 & 1 & $\begin{array}{l}\text { Aline Maria Men- } \\
\text { des Mola Sávio }\end{array}$ & 18 & 3 \\
\hline Lúcia Avelar & 17 & 1 & $\begin{array}{l}\text { Cristiano dos } \\
\text { Santos Parnaíba }\end{array}$ & 17 & 2 \\
\hline Gaudêncio Torquato & 17 & 1 & $\begin{array}{l}\text { Fernanda Terezi- } \\
\text { nha de Almeida }\end{array}$ & 17 & 1 \\
\hline Emma Siliprandi & 17 & 1 & $\begin{array}{l}\text { Suelyn Cristina } \\
\text { Carneiro da Luz }\end{array}$ & 17 & 2 \\
\hline David Kirkpatrick & 17 & 1 & $\begin{array}{l}\text { Silvia Regina } \\
\text { Ferreira }\end{array}$ & 17 & 1 \\
\hline Amadeu Amaral & 16 & 1 & $\begin{array}{l}\text { Wellington César } \\
\text { Martins Leite }\end{array}$ & 16 & 1 \\
\hline Pierre Bourdieu & 16 & $\begin{array}{l}\text { Não há } \\
\text { predominância }\end{array}$ & - & - & - \\
\hline
\end{tabular}




\section{Teorias de base}

A pesquisa nas dissertações de mestrado também abordou as teorias de base utilizadas pelos discentes, com a finalidade de verificar como se dá a difusão dos paradigmas da Escola Latino-Americana de Comunicação na linha 1 do programa.

Pensando em América Latina e considerando somente a nacionalidade, vemos que, como foi apontado anteriormente, dos 30 autores mais citados e utilizados em toda a linha 1, 60\% dos deles são latinos: $50 \%$ brasileiros e 10\% argentinos. Se olharmos para os números pensando em toda a Escola Latino-Americana, contudo, vemos que há uma grande concentração em autores nacionais e não há exploração dos demais autores da Escola. Há de se considerar, ainda, que um dos autores de nacionalidade espanhola (a terceira nacionalidade de autores mais citados, 7\%) é Jesús Martín-Barbero, que apesar de europeu, desenvolveu suas teorias na Colômbia e é grande representante da Escola Latino-Americana.

Com a grande presença dos autores nacionais, vemos que os Estudos Latino-americanos, seguido dos Estudos Culturais, são as teorias de base mais utilizadas pelos discentes da linha 1. A presença dessas duas escolas já era prevista, uma vez que muitos autores latino-americanos elaboraram suas teorias a partir de proposições dos Estudos Culturais. É o caso, mais uma vez, de Martín-Barbero, que "recusa as ideias difundidas pela Escola de Frankfurt e pelos teóricos marxistas da comunicação e elabora sua teoria a partir de algumas proposições dos Cultural Studies" (DANTAS, 2008).

Sobre a teoria de base mais utilizada, a Escola Latino-Americana de Comunicação, o autor brasileiro mais citado nas dissertações, José Marques de Melo, é um dos maiores representantes da Escola. Segundo Melo (1999), os estudos da escola latina de comunicação conseguiu espaço e reconhecimento nas academias da América do Sul somente no final do século XX.

Logo, se nosso corpus de análise fosse dissertações de períodos anteriores, como os primeiros anos do século XXI, poderíamos ter nos deparados com outros resultados. Outro fator a ser considerado foi a aplicação dessa teoria de base: assim como surgiu, nos meados das décadas de 50, preocupado com as análises dos "fenômenos de interação simbólica mediados pela mídia" (MELO, 1999) na América Latina, constatamos que os Estudos Latino-americanos nas dissertações analisadas serviram como base para se realizar, quase que em sua totalidade, a análise de coberturas midiáticas e a análise de construção de notícia em meios de comunicação brasileiros. Quanto à mídia analisada com o aporte dos estudos latinos, houve grande presença de meios de comunicação locais (ex: Rádio UNESP FM); e de resgate histórico de meios impressos (ex: Jornal 'Coração', o Porta-Voz da Torcida Corintiana).

Dos Estudos Culturais, vimos que autores da Escola Latino-Americana de comunicação citados nas dissertações analisadas, beberam na sua fonte dos Cultural Studies para desenvolver suas teorias. Além de Martín-Barbero, podemos citar também o argentino Nestor Garcia Canclini, segundo autor que mais apareceu nas dissertações da linha 1, e a utilização dos conceitos de hibridização e mediações culturais desenvolvida pelo autor latino.

O sociólogo Manuel Castells também bebeu dos Estudos Cultuais para desenvolver seus estudos das redes também utilizados nas dissertações analisadas. Dos autores clássicos dos Estudos 
Culturais, Stuart Hall aparece em algumas das dissertações, porém não chega a entrar para a tabela dos 30 mais utilizados e citados. Quanto à mídia analisada com o aporte dos Estudos Culturais, eles apareceram em dissertações que envolveram estudos de internet e cibercultura, como perfis de Twitter e páginas de Facebook (ex: página Diário de Classe).

A Teoria Crítica da Escola de Frankfurt também apareceu nos resultados das análises, porém com menos força. Seus autores principais, como Max Horkheimer, Theodor Wiesengründ Adorno, Herbert Marcuse e Walter Benjamim, por exemplo, não apareceram na tabela dos 30 autores mais utilizados e citados. Quanto à mídia analisada com o aporte dos estudos Teoria Crítica, os aportes da Teoria apareceram associados a dissertações que analisaram processos eleitorais brasileiros (ex: Charges sobre Dilma Rousseff).

Vale ainda apontar que dos autores norte-americanos mais utilizados, Henry Jenkins e David Kirkpatrick, desenvolvem estudos sobre internet e cibercultura. Um dos autores brasileiros mais utilizados, Raquel Recuero, também é referência em pesquisas de internet, meios digitais e redes sociais virtuais. $\mathrm{O}$ dado mostra como a linha 1 do programa tem se relacionado com o tema da comunicação mediada pelas novas tecnologias digitais.

\section{Considerações finais}

Observando-se os resultados, é possível afirmar que assuntos diversos foram discutidos no último biênio, evidenciando uma variedade temática significativa. Embora haja autores que predominaram no levantamento quantitativo, não existe nenhum nome que esteve presente, de maneira decisiva, em todas as dissertações da linha. Considera-se que o principal perfil da linha é a abrangência temática e a tendência de discutir os mais variados processos midiáticos e comunicacionais, nos mais diversos meios. Temas como os meios, comunicação rural, religiosidade, cultura digital e influência e estrutura das mídias estiveram entre os variados assuntos tratados.

Embora não fosse o objeto de análise central proposto, também realizou-se um levantamento de quais as metodologias mais frequentes utilizadas, a título de ampliação dos dados aqui analisados. O levantamento bibliográfico e documental, as análises de conteúdo e as análises de enquadramento tiveram destaque. Além disso, pode-se perceber uma tendência de fortalecimento de estudos ligados à internet, cultura digital e processos midiáticos mediados pelas tecnologias digitais, que contam com metodologias adaptadas para os referenciados contextos.

Ao analisar os autores e temas trabalhados, pode-se perceber que o eixo cultural tem forte apelo nas dissertações estudadas. Processos midiático-culturais foram trabalhados e autores com grande destaque de pesquisa no eixo comunicação e cultura estiveram presentes no levantamento feito. Tanto os autores latino-americanos quanto os de outras nacionalidades que predominam tangenciam os estudos sobre cultura e trazem para as dissertações do biênio uma característica específica do Programa.

Pode-se perceber ainda que, por mais que a internet tenha difundido e possibilitado o acesso a diversas bases de dados, revistas científicas e anais de importantes encontros científicos da área de comunicação, são os livros e os capítulos de livros as principais fontes consultadas. Outra característica marcante é que, embora exista a presença de autores "clássicos" em parte considerável das dissertações, a maioria das referências e citações trazem discussões relativamente 
atuais, realizadas a partir dos anos de 1990. Essas tendências podem ser explicadas, provavelmente, pela predominância de temas atuais nas discussões.

Importante ressaltar também, que embora o perfil da linha deva levar em conta o todo das referências e citações, foi feito um trabalho para constatar quais autores realmente tem apelo teórico no todo e quais tem predominância nítida em apenas uma ou duas dissertações. Após se fazer esse trabalho, algumas constatações e análises se tornaram possíveis.

Nestor Garcia Canclini, José Marques de Melo, Laurence Bardin, Manuel Castells e, em menor escala, Jesus Martín-Barbero são alguns dos autores que aparecem em várias pesquisas diferentes e que tem destaque especial no perfil da linha 1, aqui analisado. Já outros autores como Roland Barthes, Mike Featherstone, Lucia Santaella e Mario Kaplún, embora muito citados e referenciados, aparecem especificamente em uma ou duas dissertações com grande presença, sendo importantes para o todo, mas não configurando tendência da linha pesquisada.

Enfim, em uma análise global, percebe-se que o perfil da linha 1 do Programa de Pós-graduação em Comunicação ainda não passa verdadeiramente por diversos autores latino-americanos (principalmente fora do eixo Brasil-Argentina), tendo nomes específicos e predominância nítida para autores brasileiros diversos.

Como já referenciados anteriormente, os Estudos Culturais tem destaque considerável dentro das pesquisas analisadas, assim como autores clássicos da Escola Latino-americana de Comunicação. Porém, o que é mais perceptível é que há predominância nítida de autores brasileiros, seguidos por argentinos, mas que não há destaque para outros países da região. Não se nota nos pesquisadores da Linha 1 uma tendência a utilizar bibliografias de outros autores latinoamericanos, fora do eixo citado.

\section{Referências}

DANTAS, José Guibson Delgado. Teoria das mediações culturais: Uma Proposta de Jesús Martín-Barbero para o Estudo de Recepção. In: INTERCOM, 10., 2008, São Luis. Papers. São Luis: Intercom, 2008. p. 1 - 10. Disponível em: <http://www.intercom.org.br/papers/regionais/ nordeste2008/resumos/R12-0015-1.pdf >. Acesso em: 30 abr. 2015.

DUARTE, Jorge; BARROS, Antonio (orgs.). Métodos e técnicas de pesquisa em comunicação. 2. ed. São Paulo: Atlas, 2011.

MELO, José Marques de. Paradigmas da escola latino-americana de comunicação. Comun. Inf., Goiânia, v. 2, n. 2, p.188-203, jul. 1999. Disponível em: <http://www.revistas.ufg.br/index. $\mathrm{php} / \mathrm{ci} /$ article/viewFile/22854/13595>. Acesso em: 01 maio 2015. 